SHS DS DTI, Erlangen, Germany; ${ }^{4}$ Department of Dermatology, FriedrichAlexander University (FAU) Erlangen-Nürnberg and Universitätsklinikum Erlangen, Erlangen, Germany

Background: We have previously reported that the presence of musculoskeletal pain in psoriasis patients is associated with a higher risk of developing psoriatic arthritis (PsA) (1). Furthermore, a subset of psoriasis patients shows evidence for structural entheseal lesions (SEL) in their hand joints (2), sometimes also referred as "Deep Koebner Phenomenon", which are highly specific for psoriatic disease and virtually absent in healthy controls, rheumatoid arthritis and hand osteoarthritis patients (2-4). However, it remains unclear whether SEL alone or in combination with musculoskeletal pain are associated with the development of PsA.

Objectives: To test whether the presence of SEL in psoriasis patients increases the risk for progression to PsA and how this is related to the presence of musculoskeletal pain.

Methods: Psoriasis patients without evidence of PsA were enrolled in a prospective cohort study between 2011 and 2018. All patients underwent baseline assessment of SEL in their $2^{\text {nd }}$ and $3^{\text {rd }} \mathrm{MCP}$ joints by high-resolution peripheral quantitative computed tomography (HR-pQCT). The risk of PsA development associated with SEL and arthralgia was explored using survival analyses and multivariable Cox regression models.

Results: 114 psoriasis patients (72 men/42 women) with a mean (SD) follow-up duration of 28.2 (17.7) months were included, 24 of whom developed PsA (9.7 /100 patient-years, $95 \% \mathrm{Cl} 6.2$ to 14.5$)$ during the observation period. Patients with SEL ( $\mathrm{N}=41)$ were at higher risk of developing PsA compared to patients without such lesions $(21.4 / 100$ patient-years, $95 \% \mathrm{Cl} 12.5$ to $34.3, \mathrm{HR}$ $5.10,95 \% \mathrm{Cl} 1.53$ to $16.99, \mathrm{p}=0.008$ ) (Kaplan Meier plot A). Furthermore, while patients without arthralgia and without SEL had a very low progression rate to PsA $(1 / 29 ; 3.4 \%)$, patients with arthralgia but no SEL showed higher progression (5/33; 15.2\%), which was in line with previous observations (1) (Kaplan Meier plot B). Presence of SEL further enhanced the risk for progression to PsA both in the absence $(6 / 16 ; 37.5 \%)$ and presence $(6 / 14 ; 42.8 \%)$ of arthralgia with the highest progression rate in those subjects with both arthralgia and SEL $(p<0.001$ by log rank test for trend) (Kaplan Meier plot B).

Conclusion: Presence of SEL is associated with an increased risk of developing PsA in patients with psoriasis. If used together with pain, SEL allow defining subsets of psoriasis patients with very low and very high risk to develop PsA. References:

[1] Faustini F et al. Ann Rheum Dis. 2016;75:2068-2074

[2] Simon D et al. Ann Rheum Dis. 2016;75:660-6

[3] Finzel $S$ et al. Ann Rheum Dis. 2011;70:122-7

[4] Finzel S et al. Arthritis Rheum. 2011;63:1231-6
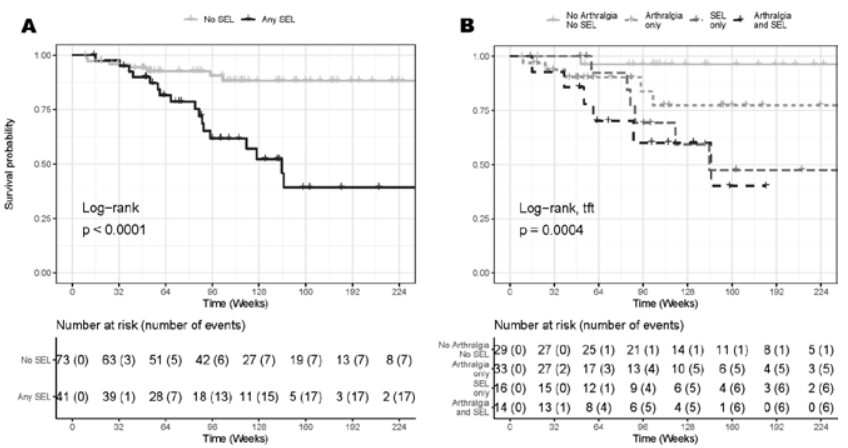

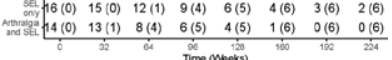

Disclosure of Interests: David Simon Grant/research support from: Else Kröner-Memorial Scholarship, Novartis, Consultant of: Novartis, Lilly, Koray Tascilar: None declared, Arnd Kleyer Consultant of: Lilly, Gilead, Novartis,Abbvie, Speakers bureau: Novartis, Lilly, Sara Bayat Speakers bureau: Novartis, Eleni Kampylafka Speakers bureau: Novartis, BMS, Janssen, Axel Hueber Grant/ research support from: Novartis, Lilly, Pfizer, Consultant of: Abbvie, BMS, Celgene, Gilead, GSK, Lilly, Novartis, Speakers bureau: GSK, Lilly, Novartis, Jürgen Rech Consultant of: BMS, Celgene, Novartis, Roche, Chugai, Speakers bureau: AbbVie, Biogen, BMS, Celgene, MSD, Novartis, Roche, Chugai, Pfizer, Lilly, Louis Schuster: None declared, Klaus Engel: None declared, Michael Sticherling Grant/research support from: Novartis, Consultant of: Advisory boards Abbvie, Celgene, Janssen Cilag, Lilly, Pfizer, MSD, Novartis, Amgen, Leo, Sanofi, UCB, Speakers bureau: Abbvie, Celgene, Janssen Cilag, Leo, MSD, Novartis, Pfizer, Georg Schett Speakers bureau: AbbVie, BMS, Celgene, Janssen, Eli Lilly, Novartis, Roche and UCB

DOI: 10.1136/annrheumdis-2020-eular.1524

\section{OP0052 COMPARISON OF PATIENTS WITH PSORIATIC ARTHRITIS (PSA) AND INVESTIGATOR-DEFINED AXIAL PSA TO PATIENTS WITH PSA AND ELEVATED PATIENT-REPORTED SPINE PAIN: FINDINGS FROM THE CORRONA PSORIATIC ARTHRITIS/ SPONDYLOARTHRITIS (PSA/SPA) REGISTRY}

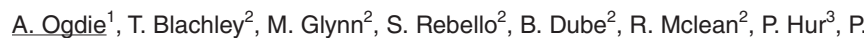
J. Mease ${ }^{4}$. 'University of Pennsylvania School of Medicine, Philadelphia, United States of America; ${ }^{2}$ Corrona, LLC, Waltham, United States of America; ${ }^{3}$ Novartis Pharmaceuticals Corporation, East Hanover, United States of America; ${ }^{4}$ Swedish Medical Center/Providence St. Joseph Health and University of Washington, Seattle, United States of America

Background: Efforts are underway by GRAPPA and ASAS to define axial disease in psoriatic arthritis (axPsA). ${ }^{1}$ AxPsA is typically diagnosed based on clinical evaluation and judgement, imaging, and patient-defined axial symptoms. In the MAXIMISE trial, part of the inclusion criteria for axPsA required patients to have a BASDAI $\geq 4$ and patient-reported spine pain $\geq 40$ in addition to clinician judgement. ${ }^{2}$

Objectives: To compare characteristics of patients with PSA and investigator-identified axPsA to patients with PsA with BASDAI $\geq 4$ and patient-reported spine pain $\geq 40$.

Methods: Adult patients with PsA enrolled in the registry from March 2013-December 2019 were included. Investigators identified the subset of patients with axPsA based on clinical assessments, imaging, and laboratory workup. All patients completed a BASDAI questionnaire and spine pain VAS Patients with investigator-identified axPsA were compared with those who had BASDAI $\geq 4$ and spine pain VAS $\geq 40$ (elevated spine symptoms; non-mutually exclusive groups). Presence of other manifestations at enrollment was also evaluated: enthesitis (SPARCC enthesitis count $>0$ ), dactylitis (dactylitis count $>$ 0 ), peripheral arthritis (PA; tender and/or swollen joint count $>0$ ), nail psoriasis (VAS $>0$ ), skin psoriasis (affected body surface area $>0 \%$ ). The prevalence of investigator-defined axPsA and elevated spine symptoms, alone and with other manifestations, was summarized for all patients and those who initiated biologics at enrollment using frequency counts and percentages.

Results: Of 3393 patients with PsA, 391 (11.5\%) had investigator-defined axPsA and $863(25.4 \%)$ had elevated spine symptoms (Figure 1A); $127(3.7 \%)$ patients met both criteria. In the total population with PsA, 2982 patients had $\geq 1$ PsA manifestation when axPsA was investigator defined, of whom 2235 (74.9\%) had multiple manifestations. Among those with $\geq 1$ manifestation, the most common presentations were PA + skin (14.6\%), skin (13.1\%), and PA + nail + skin $(11.3 \%)$. When using the criteria for elevated spine symptoms, 2996 patients had $\geq 1 \mathrm{PsA}$ manifestation, of whom 2299 (76.7\%) had multiple manifestations. Among those with $\geq 1$ manifestation, the most common presentations were skin (12.3\%), PA + skin $(11.2 \%)$, and PA + nail + skin (8.8\%). Of 769 patients who initiated a biologic at enrollment, 109 (14.2\%) had investigator-defined axPsA and $270(35.1 \%)$ had elevated spine symptoms (Figure 2A). Among all biologic initiators with PsA, 733

Figure 1. Prevalence of (A) PSA Disease Manifestations and (B) Other Manifestations With Axial Disease in the Overall Population

A

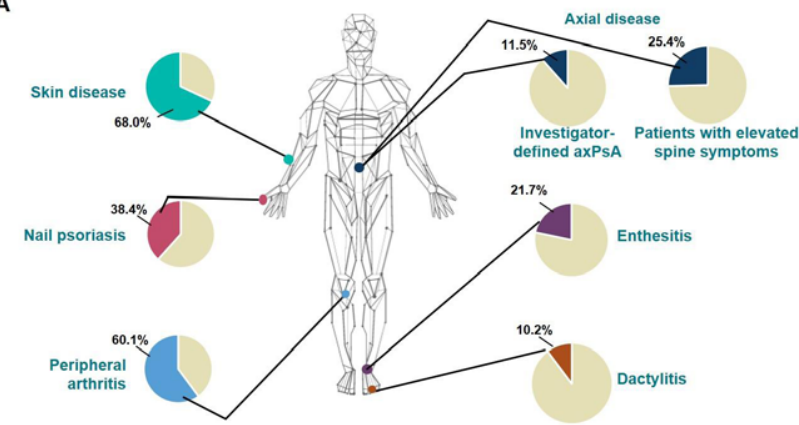

B

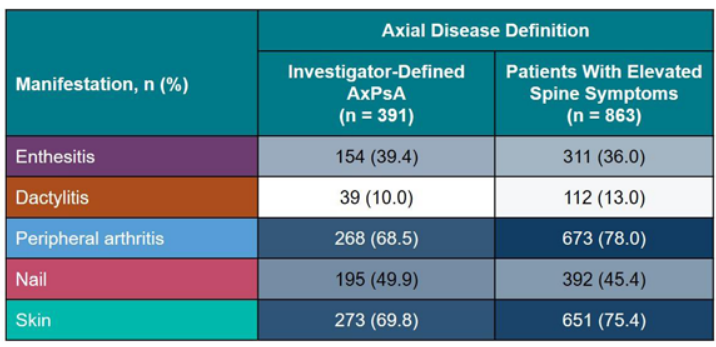
The heat map represents the frequency of any 2 domain combinations by the range of blue shades, with the darkes
blue color specifying the highest frequency and the lightest blue specifying the lowest frequency of combinations. 
had $\geq 1$ PsA manifestation when axPsA was investigator defined, of whom 630 $(85.9 \%)$ had multiple manifestations; the most common presentations were PA + skin $(16.2 \%), \mathrm{PA}+$ skin + nail $(12.8 \%)$, and enthesitis + PA + nail + skin $(7.8 \%)$. When using the criteria for elevated spine symptoms, 732 biologic initiators had $\geq$ 1 disease manifestation, of whom $650(88.8 \%)$ had multiple manifestations; the most common presentations were PA + skin (11.7\%), PA + skin + nail (8.5\%), and $\mathrm{PA}+\operatorname{axPsA}+$ skin $(6.3 \%)$. The prevalence of skin, PA, and dactylitis was higher in those with elevated spine symptoms vs investigator-defined $\operatorname{axPsA}$, whereas the prevalence of enthesitis was higher in those with investigator-defined axPsA (Figure 1B and 2B).

Figure 2. Prevalence of (A) PsA Disease Manifestations and (B) Other Manifestations With Axial Disease in the Biologic Initiator Population

A

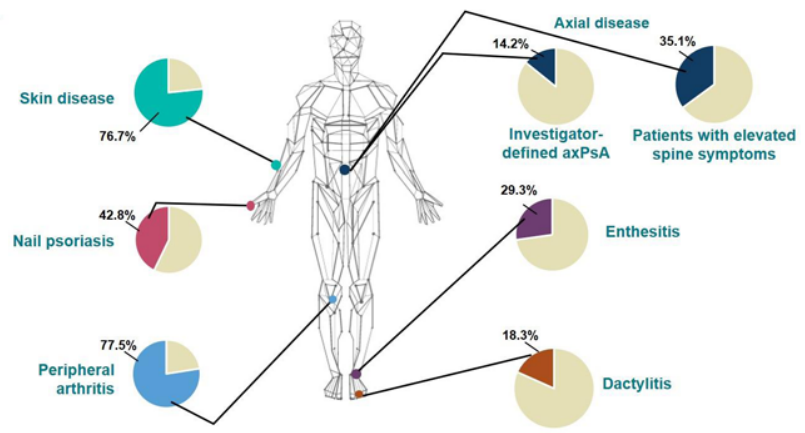

B

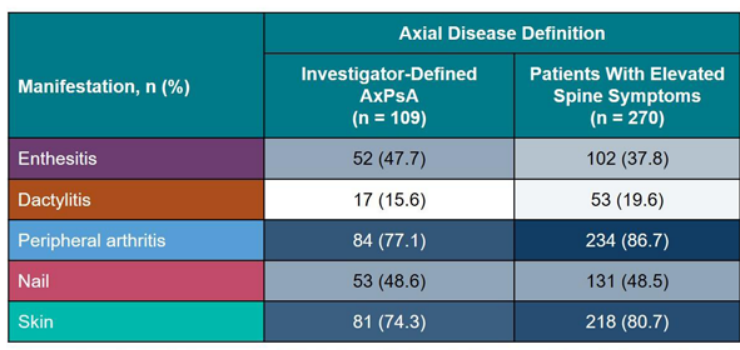

The heat map represents the frequency of any 2 domain combinations by the range of blue shades, with the darkest The heat map represents the frequency of any 2 domain combinations by the range of blue shades, with the darkest
blue color specifying the highest frequency and the lightest blue specifying the lowest frequency of combinations.

Conclusion: In the Corrona PsA/SpA Registry, there was a higher number of patients with elevated spine symptoms than with investigator-defined axPsA; these patients also had more coexisting manifestations. Although they may have had other reasons for back pain (ie, degenerative spine disease or central sensitization), it is possible that axPsA could be present in some and this warrants further evaluation.

References:

[1] Goel N, et al. J Rheumatol. 2019;95(Suppl):54-7.

[2] Baraliakos X, et al. Ann Rheum Dis. 2019;78:195-6.

Disclosure of Interests: Alexis Ogdie Grant/research support from: Pfizer to Penn, Novartis to Penn, Amgen to Forward/NDB, Consultant of: Abbvie, Amgen, Bristol-Myers Squibb, Celgene, Corrona, Janssen, Eli Lilly, Novartis, Pfizer, TayIor Blachley Employee of: Corrona, LLC, Meghan Glynn Shareholder of: Corrona, LLC - shareholder, Grant/research support from: Pfizer - grant/research support, Employee of: Corrona, LLC - employment, Sabrina Rebello Employee of: Corrona, LLC, Blessing Dube Employee of: Corrona, LLC, Robert McLean Employee of: Corrona, LLC, Peter Hur Employee of: Novartis Pharmaceuticals Corporation, Philip J Mease Grant/research support from: Abbott, Amgen, Biogen Idec, BMS, Celgene Corporation, Eli Lilly, Novartis, Pfizer, Sun Pharmaceutical, UCB - grant/research support, Consultant of: Abbott, Amgen, Biogen Idec, BMS, Celgene Corporation, Eli Lilly, Novartis, Pfizer, Sun Pharmaceutical, UCB - consultant, Speakers bureau: Abbott, Amgen, Biogen Idec, BMS, Eli Lilly, Genentech, Janssen, Pfizer, UCB speakers bureau

DOI: 10.1136/annrheumdis-2020-eular.1072

\section{OP0053 SECUKINUMAB IMPROVES CLINICAL AND IMAGING OUTCOMES IN PATIENTS WITH PSORIATIC ARTHRITIS AND AXIAL MANIFESTATIONS WITH INADEQUATE RESPONSE TO NSAIDS: WEEK 52 RESULTS FROM THE MAXIMISE TRIAL}

X. Baraliakos ${ }^{1}$, L. Gossec ${ }^{2}$, E. Pournara ${ }^{3}$, S. Jeka ${ }^{4}$, R. Blanco ${ }^{5}$, S. D'angelo ${ }^{6}$, G. Schett ${ }^{7}$, B. Schulz ${ }^{3}$, M. Rissler ${ }^{3}$, K. Nagar ${ }^{8}$, C. Perella ${ }^{3}$, L. C. Coates ${ }^{9}$. ${ }^{1}$ Rheumazentrum Ruhrgebiet Herne, Ruhr-University Bochum, Bochum, Germany; ${ }^{2}$ Sorbonne Universités, Paris, France; ${ }^{3}$ Novartis Pharma AG, Basel, Switzerland; ${ }^{4}$ 2nd University Hospital, CM UMK, Bydgoszcz, Poland; ${ }^{5} \mathrm{Hospital}$
Universitario Marqués de Valdecilla, Santander, Spain; ${ }^{6}$ Rheumatology Department of Lucania and Rheumatology Institute of Lucania (IRel), San Carlo Hospital of Potenza, Potenza, Italy; ${ }^{7}$ University of Erlangen-Nuremberg, Erlangen, Germany; ${ }^{8}$ Novartis Healthcare Pvt. Ltd., Hyderabad, India;

${ }^{9}$ University of Oxford, Oxford, United Kingdom

Background: Although axial disease may affect up to $70 \%$ of patients (pts) with Psoriatic Arthritis (PsA), evidence on the efficacy of biologics in the treatment of axial manifestations in such pts is limited, ${ }^{1}$ particularly as validated classification criteria for this subtype of PsA are not yet available. MAXIMISE (NCT02721966) is the first randomised controlled trial evaluating the efficacy of a biologic in the management of the axial manifestations of PsA and showed that secukinumab (SEC) 300 and $150 \mathrm{mg}$ provided rapid and significant improvement in ASAS20 responses in these pts through week (Wk) $12 .^{2}$

Objectives: To present 52 wks efficacy results and imaging data from the MAX IMISE trial.

Methods: This phase $3 \mathrm{~b}$, double-blind, placebo (PBO)-controlled, multicentre 52-wk trial included 498 pts (aged $\geq 18$ years) with a diagnosis of PsA and classified by CASPAR criteria, spinal pain VAS score $\geq 40 / 100$ and BASDAI score $\geq 4$ despite use of at least two NSAIDs. Pts were randomised to SEC $300 \mathrm{mg}$ $(\mathrm{N}=167)$ or SEC $150 \mathrm{mg}(\mathrm{N}=165)$ or PBO $(\mathrm{N}=166)$ wkly for 4 wks and every 4 wks thereafter. At Wk 12, PBO pts were re-randomised to SEC $300 / 150 \mathrm{mg}$. The primary endpoint was ASAS20 response with SEC $300 \mathrm{mg}$ at Wk 12 . The key secondary endpoint was ASAS20 response with SEC $150 \mathrm{mg}$ at Wk 12. Wk 52 data are presented as observed. Bone marrow oedema of the entire spine and sacroiliac joints were assessed centrally with Berlin MRI scores at Baseline, Wk 12 and Wk 52.

Results: Primary and key secondary endpoints were met; ASAS20 responses were sustained and increased further through Wk $52.75 \% / 79.7 \%$ of the PBO pts re-randomised at Wk 12 to SEC $300 / 150 \mathrm{mg}$ achieved ASAS20 response at Wk 52 (Figure 1). ASAS40 responses at Wk 52 were $69.1 \%$ [SEC $300 \mathrm{mg}$ ], 64.5\% [SEC $150 \mathrm{mg}$ ], 62.5\% [PBO-SEC $300 \mathrm{mg}$ ], and 54.1\% [PBO-SEC $150 \mathrm{mg}$ ]. At baseline, 59.5\% [SEC $300 \mathrm{mg}$ ], 53.5\% [SEC $150 \mathrm{mg}$ ] and $64.2 \%$ [PBO] of the pts had positive MRIs for the sacroiliac joints and/or the spine with Berlin MRI score $\geq 1$. The reductions of Berlin MRI score for entire spine and sacroiliac joints were statistically significant for pts treated with SEC 300/150 mg vs. placebo (Figure 2 a and b). There were no new or unexpected safety findings.

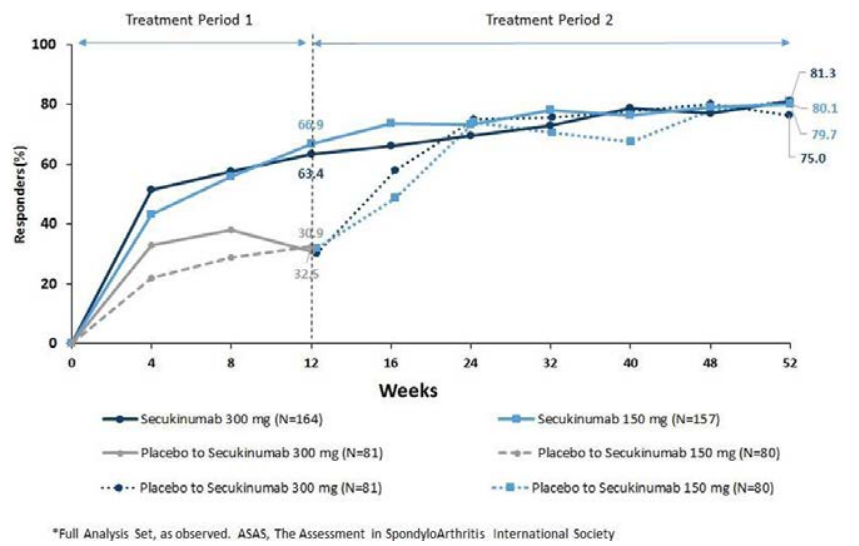

Figure 1. ASAS20 Response over $52 \mathrm{Wks}^{\star}$

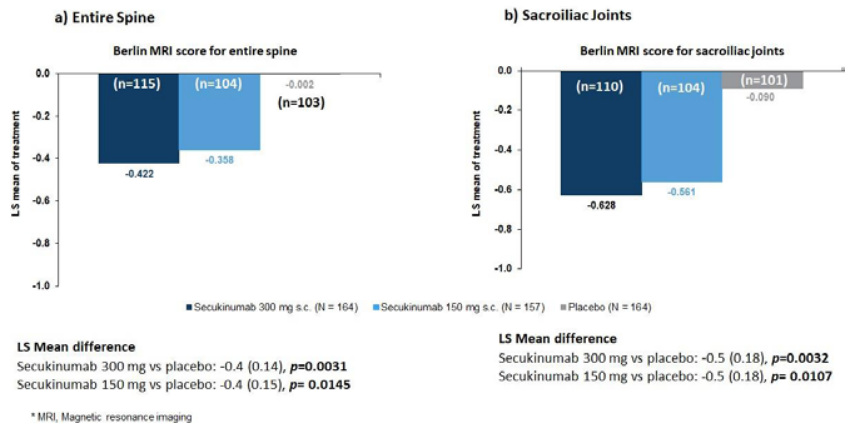

Figure 2. Total Berlin MRI score for the Entire Spine and Sacroiliac Joints at Wk 12

Conclusion: Secukinumab improved all evaluated ASAS responses through Wk 52 in PsA pts with axial manifestations and inadequate responses to NSAIDs 